

\title{
O desdobramento da tragédia da política no Brasil ${ }^{1}$
}

\author{
Brozil. An ongoing trajedy
}

Peter Evans*

\section{Resumo}

O artigo apresenta uma discussão sobre a trajetória política recente do Brasil. Para isso, apresentam-se as transições desde o impeachment contra a presidenta Rousseff até a vitória eleitoral de Jair Bolsonaro. A análise se centra nas caraterísticas dos diferentes momentos políticos, em particular, na agenda de políticas públicas. A natureza das transições está explicada com base no jogo das elites políticas e econômicas. $\mathrm{O}$ artigo recupera também elementos positivos que poderiam, potencialmente, gerar um contraponto à ideologia reacionária dos movimentos no poder desde o golpe parlamentar de 2016.

Palavras-chave: Brasil, elites, desenvolvimento.

\begin{abstract}
The article presents a discussion of Brazil's recent political trajectory focusing on three different moments: from President Rousseff's impeachment to Bolsonaro's electoral victory. The analysis underlines the characteristics of these moments and their impacts on public policy agendas. The nature of the transitions is explained based on the political process emphasizing on political and economic elites. It also recovers the positive elements that could potentially generate a counterpoint to the conservative ideology of governments since the 2016 parliamentary coup.
\end{abstract}

Keywords: Brazil, elites, development. 
A tragédia política que aconteceu nas eleições presidenciais do Brasil em 2018 era apenas uma possibilidade assustadora quando Dilma Rousseff (Presidente do Brasil, 2011-2016) proferiu seu discurso na Universidade da Califórnia em Berkeley em abril de 2018. No entanto, seu discurso forneceu um resumo convincente da dinâmica perversa que levou ao resultado das eleições de outubro de 2018. A presidenta Dilma Rousseff fez uma análise das séries de transições que transformaram o Brasil em quatro curtos anos desde sua eleição, aproveitando sua experiência como ator central no drama, sua experiência como economista política, e seu compromisso político em construir um Brasil politicamente e economicamente mais justo.

A cascata de transições no Brasil começou com a mudança dos sucessos sociais e econômicos incomuns dos primeiros anos do século XXI, liderados pelas administrações eleitas do Partido dos Trabalhadores (daqui em diante "PT"), para o regime regressivo de Michel Temer, instalado em agosto de 2016 através do que é melhor descrito como um "golpe legislativo". A próxima transição, em janeiro de 2019, para um regime dominado por Jair Bolsonaro e seus aliados, reforçará e estenderá as políticas regressivas do governo Temer, adicionando um novo nível de repressão autoritária cruel. Os contrastes entre esses três regimes não são difíceis de estabelecer. O desafio é oferecer uma explicação plausível da dinâmica que permitiu a transição do primeiro para o segundo e do segundo para o terceiro.

A tentação é concentrar toda a nossa atenção na transição mais recente - afinal, representa a mudança política mais significativa no Brasil desde a redemocratização da década de 1980 -, mas entender esse triunfo da reação exige definir um contexto maior. O discurso da presidente Dilma Rousseff ofereceu um excelente começo, destacando o caráter do primeiro desses regimes, que ela ajudou a construir.

Embora Dilma seja uma economista com um entendimento sofisticado de como a economia brasileira opera, sua apresentação na UC Berkeley definiu os sucessos das administrações do PT de maneira simples e direta: vidas melhoradas para os brasileiros comuns. As manifestações da política concreta estavam "expandindo o acesso da população a políticas públicas, como educação, saúde e outros serviços que a população brasileira nunca teve, de eletricidade a água encanada, mas acima de tudo educação". Talvez ainda mais importante tenha sido a mudança na visão que as pessoas pobres tinham do futuro:"Demos as pessoas esperança que seus filhos tenham uma vida melhor do que tiveram". Para Dilma, "saber que as pessoas acreditavam que teriam uma vida melhor"era seu "maior orgulho como presidente do Brasil".

A expansão de programas de previdência social, como o BPC (Benefício de Prestação Continuada), e de regimes rurais e previdenciários fizeram parte da expansão geral da rede de proteção social. Talvez o mais conhecido seja o programa Bolsa Família de transferência condicionada de renda. O Bolsa Família alcançou dezenas de milhões de brasileiros muito pobres. Ainda mais importante em termos da magnitude dos recursos transferidos para os pobres foi a reformulação do mercado de trabalho. 
Sob Luiz Inácio Lula da Silva (2003-2010) e Dilma Rousseff (2011-2016) - popularmente conhecido como "Lula" e "Dilma" - quase quatro mandatos do governo do PT ajudaram os trabalhadores a escapar do trabalho precário ao "re-formalizar" o trabalho. De acordo com Berg (2010: 7), a primeira década do século XXI viu "o crescimento formal do emprego ultrapassando o crescimento informal do emprego em uma proporção de três para um". Se considerarmos a década entre 2003 e 2013 como o período de referência, a proporção de trabalhadores "informais" nos empregos do setor privado encolheu quase $40 \%$. A proporção de trabalhadores registrados de acordo com as leis trabalhistas e, portanto, com os direitos formais decorrentes dessas leis, aumentou de pouco mais da metade da força de trabalho para $64 \%$ ao longo da década. Talvez a política mais importante de todas tenha sido aumentar o salário mínimo real.

O impacto dos aumentos reais no salário mínimo foi muito além das mudanças nas rendas dos trabalhadores cujos salários foram diretamente afetados. O nível do salário mínimo é usado como ponto de referência para os trabalhadores que ainda estão empregados "informalmente" (ou seja, fora da estrutura da legislação trabalhista), gerando um efeito flutuante não oficial em seus meios de subsistência. Talvez ainda mais importante, a Constituição Federal de 1988 vinculou uma variedade de rendas não-salariais ao salário mínimo, incluindo as aposentadorias. Assim, o salário mínimo serve como uma espécie de "salário social" geral, com amplo impacto na sociedade como um todo. Segundo uma estimativa, $64 \%$ da redução da desigualdade no Brasil de 1995 a 2005 pode ser atribuída ao aumento do salário mínimo².

O fortalecimento da "rede de segurança social", combinada com melhorias no mercado de trabalho, alterou os níveis gerais de bem-estar econômico. Apesar do crescimento econômico geral relativamente modesto, a renda mediana das famílias aumentou 30\% entre 2003 e 2013, indicando um padrão de crescimento mais inclusivo. A desigualdade, medida pelo índice de Gini, caiu de 0,55 para 0,50 entre 2001 e 2012 (MINISTÉRIO DO PLANEJAMENTO, 2014, p. 11), e a taxa de crescimento da renda no quintil inferior foi três vezes maiordo que no quintil superior (MINISTÉRIO DO PLANEJAMENTO, 2014, p. 16).

Até o Banco Mundial concordou que as três primeiras administrações do PT constituíam "anos dourados" do ponto de vista dos brasileiros comuns, resumindo os ganhos da seguinte forma: "O progresso econômico e social do Brasil entre 2003 e 2014 tirou 29 milhões de pessoas da pobreza e a desigualdade caiu significativamente (o coeficiente de Gini caiu 6,6 pontos percentuais no mesmo período, de 58,1 para $51,5)$. O nível de renda dos $40 \%$ mais pobres da população aumentou, em média, 7,1\% (em termos reais) entre 2003 e 2014, em comparação com um crescimento de 4,4\% na renda da população como um todo ${ }^{3 \prime \prime}$.

Se "avançarmos"quatro anos desde a reeleição da presidente Dilma Rousseff entre 2014 e 2018, quando o regime de Temer cumpriu amplamente seus objetivos, a direção da mudança foi revertida. A insistência do novo regime em reduzir gastos 
sociais, desviando as receitas do governo para garantir os retornos do capital financeiro mudou o cenário da proteção social. Fleury e Pinho (2018: 30) resumem as consequências de bem-estar da política atual do governo, dizendo: "O Brasil está passando por um processo sem precedentes de destruição de seu estado de bem-estar social (incipiente)." Simultaneamente, o novo governo decretou o que pode ser a mudança mais substancialmente regressiva na legislação trabalhista em 75 anos, forçando os trabalhadores do Brasil a voltarem ao trabalho precário (OLIVEIRA, 2018, p. 334).

A natureza abrupta e completa dessa transição é desconcertante. A explicação mais poderosa e parcimoniosa parece simples demais: as elites capitalistas (dominadas principalmente pelo capital financeiro) não estavam dispostas a permitir que seus interesses fossem prejudicados pelas instituições democráticas. Por isso, usaram seu poder para refazer instituições de maneira a produzir resultados mais consistentes com seus interesses.

Seus aliados nos principais partidos políticos "centristas" acumularam poder institucional e político suficiente para realizar com sucesso o que equivalia a um golpe duplo - primeiro, o impeachment de Dilma e, em seguida, a eliminação dos direitos políticos de Lula. Isso não quer dizer que eles foram capazes de alcançar exatamente os resultados políticos que prefeririam, mas tiveram inquestionavelmente sucesso em mudar as regras do jogo a seu favor. Depois de quatro eleições presidenciais vencidas em plataformas nas quais a proteção e redistribuição social eram peças-chave, eles podem aproveitar a perspectiva de um futuro político em que não precisarão se preocupar com o fato de essas questões serem levadas a sério.

Esta é, reconhecidamente, uma caracterização dura das elites brasileiras e do capitalismo brasileiro como um sistema. Sugere que a égide do capitalismo condena a possibilidade de implementar agendas redistributivas no século XXI, pelo menos no Sul Global e talvez um conjunto mais amplo de países geralmente não são considerados parte do Sul Global. Essa análise é muito dura, mas ainda é um trampolim útil para pensar sobre o que aconteceu no Brasil.

Mesmo que a proposição de que os resultados políticos sejam dirigidos principalmente pelos interesses econômicos das elites à custa da democracia seja correta, dimensões políticas e ideológicas cruciais devem ser adicionadas à equação. Elementos ideológicos e políticos diferentes são primários em cada transição e seus efeitos são cumulativos nas duas transições.

Para entender a transição de Dilma para Temer, é necessário ampliar a análise política do PT. É preciso reconhecer que os regimes do PT eram menos robustos e eficazes do que pareciam, tanto em sua capacidade de proporcionar os benefícios econômicos e sociais necessários para cimentar a lealdade de seus constituintes naturais quanto em termos de sua capacidade de construir a infraestrutura organizacional e mobilizacional necessária para defender sua agenda de ataques da elite. 
As sementes da transição de Temer para Bolsonaro foram semeadas, mas os principais componentes adicionais desempenharam papéis cruciais: o regime de Temer foi um sucesso total na entrega da agenda econômica e social do capital, mas um fracasso sombrio. A falta de legitimidade popular impossibilitou a eleição do próximo presidente entre a liderança dos principais partidos centristas - o Partido da Social Democracia Brasileira (PSDB) e o Partido do Movimento Democrático Brasileiro (PMDB) - cortando o caminho mais óbvio para a continuação do novo regime.

Para piorar as coisas para aqueles que aspiram a continuar a agenda de Temer, a persistência do carisma político de Lula fez com que ele continuasse sendo um candidato presidencial viável. Ele precisou ser eliminado da arena eleitoral para garantir que a austeridade continuasse desimpedida. Isso exigia uma dança jurídica complexa, na qual o primeiro movimento era a elevação da "anticorrupção" à posição primordial na agenda política nacional, com exclusão de temáticas políticas substanciais como equidade e redistribuição. O segundo movimento foi limpar legalmente Lula do mapa eleitoral.

Mesmo depois de identificada a sequência permanecem questões políticas fundamentais. Antes de tudo, por que foi tão fácil derrubar o que parecia ser, no primeiro mandato de Dilma, um projeto político "hegemônico" (BRAGA, 2012)? Visto em perspectiva comparativa, o PT estava entre os partidos progressistas mais eficazes do mundo Sul. No contexto de uma economia política nacional completamente dominada pelo capital financeiro, o sucesso do partido foi histórico. No entanto, a história do PT no século XXI deixa claro que, dentro dos limites impostos pelo capitalismo contemporâneo, até o governo mais progressivo e eficaz pode oferecer apenas um conjunto limitado de melhorias na vida das pessoas. A maioria dos empregos permaneceu precária e a capacidade do Estado de entregar serviços públicos essenciais ainda era um projeto em construção. Décadas de progresso em uma taxa semelhante à alcançada de 2003 a 2014 teriam sido necessárias para transformar completamente a vida dos brasileiros comuns e obter sua lealdade.

OPT poderia ter empurrado o lado redistributivo de seu programa econômico para mais ou mais rápido? Dados os limites impostos pela conjuntura geral das instituições políticas brasileiras, a resposta é "provavelmente não". Ganhar a presidência, mesmo quatro vezes seguidas, não foi suficiente. Forçado a confiar em aliados parlamentares não confiáveis e oportunistas - principalmente os membros do Congresso afiliados ao PMDB - o PT tinha um espaço político muito limitado.

As políticas que desafiavam as enormes taxas de retorno que as finanças podiam apropriar-se,em detrimento do setor produtivo da economia brasileira, estavam nos limites do que o PT poderia tentar. Dilma fez esforços mais sérios do que Lula nessa direção, mas suas ações vieram numa época em que as condições econômicas globais favoráveis que permitiram o crescimento da economia brasileira nos primeiros anos do século XXI começaram a recuar. O crescimento já estava começando a diminuir em 2014, e a economia encolheu em 2015 e 2016, diminuindo a capacidade do governo 
de prestar serviços e empregos a brasileiros comuns e reforçando a determinação das elites econômicas de destituir o governo. Previsivelmente, os especialistas recusaramse a considerar a crise de problemas cíclicos típicos do crescimento capitalista, atribuindo-a aos efeitos de políticas "populistas" destinadas à redistribuição. ${ }^{4}$

Apesar desses limites, o PT não conseguiu reunir uma resistência mais robusta ao ataque político durante o segundo mandato de Dilma, dado que o partido havia trazido benefícios substanciais para o eleitorado mais pobre, o que é intrigante. Os cientistas sociais brasileiros produziram um conjunto impressionante de análises dissecando a estratégia do PT e suas falhas. ${ }^{5} \mathrm{~A}$ crítica mais reveladora é que uma estratégia política fundada na construção de alianças com partidos centristas e capital financeiro levou à negligência da mobilização.Esta crítica começa com a relação do partido com sua base sindical tradicional. Mesmo durante o segundo mandato de Lula, os pesquisadores argumentaram que a Central Única dos Trabalhadores (CUT) havia abandonado seu foco na organização e mobilização (ver Sluyter-Beltrão, 2010). Como a economia vacilou durante o segundo mandato de Dilma, a rebelião nas fileiras do trabalho aumentou vertiginosamente. Segundo Bastos (2018: 17), o ano de 2013 registrou um número recorde de 2.050 greves e o terceiro maior número de horas perdidas para greves na história brasileira.

O foco do PT em alianças com partidos centristas também teve efeitos corrosivos indiretos. Contar com aliados políticos corruptos levou o PT a se envolver nas próprias práticas corruptas (mais famosa no escândalo do "mensalão" de 2005; ver o artigo de McKenna, 2018). Mesmo que se adote a interpretação menos negativa possível de que essa corrupção estava a serviço da aprovação de legislação progressista, não enriquecendo os líderes individuais do PT - ainda era fundamentalmente destrutiva a maneira como os brasileiros comuns viam o partido.

Reconhecendo os limites estruturais da posição política do PT, devemos voltar aos dois principais componentes ideológicos que foram fundamentais para permitir a transição de Temer para Bolsonaro: santificar a luta contra a corrupção como valor político primordial e elaborar a estratégia de "lei" que retirou Lula do campo de batalha político.

Ninguém pode se opor às campanhas contra a corrupção. O fato de a corrupção ser incontestável em quase todos os sistemas políticos e violar as normas formais de todas elas. A capacidade das elites de prosperar com a corrupção é uma forma de injustiça muito mais direta e fácil de resolver. Entender os efeitos estruturais de uma política ruim. Lutar contra a corrupção é a maneira mais fácil de conquistar a lealdade da classe média. A melhor maneira de minar um político é rotulá-lo de corrupto.

Uma vez que o PT foi contaminado por conexões com a corrupção, suas reivindicações de ser um tipo diferente de partido, dedicado a perseguir fins programáticos em vez de seus próprios interesses, foram minadas. Com o PT manchado, as acusações de corrupção contra Lula pareciam mais plausíveis. Isso, por sua vez, abriu as portas 
para a "lei". O juiz Sérgio Moro foi capaz de mobilizar o judiciário para perseguir um caso duvidoso contra Lula com rapidez e profundidade draconianas, enquanto acusações de corrupção contra a liderança dos partidos centristas (por exemplo, Temer e Aécio Neves) foram deixadas sem perseguição. ${ }^{6}$

As consequências da eliminação de Lula da corrida presidencial foram esmagadoras. Antes de ser preso, Lula estava com mais de $30 \%$ de votos, enquanto Bolsonaro pesquisava um pouco mais da metade disso. Como a presidente Dilma Rousseff apontou em seu discurso na UC Berkeley, o fracasso político dos partidos centristas, combinado com a remoção de Lula através da prisão, "abriu o cenário político do Brasil para a extrema direita". Talvez mais do que qualquer outro indivíduo, o juiz Sergio Moro merece crédito por abrir a porta para a ascensão de Bolsonaro.

Se a transição de Dilma para Temer foi chocante por seu cinismo e desrespeito pelas instituições democráticas, a transição de Temer para Bolsonaro é a mudança mais assustadora da política brasileira na história recente. Contrasta com o tom relativamente "civilizado" que domina o discurso político do Brasil desde o retorno das eleições democráticas em 1985. Suas posições misóginas, racistas e homofóbicas declaradas que preservam a admiração pelos oficiais militares que derrubaram o governo eleito democraticamente em 1964, incluindo expressamente aqueles prisioneiros civis torturados, existem para todos verem. Bolsonaro exala animosidade depreciativa em relação a toda a gama de grupos menos privilegiados da sociedade brasileira, com mulheres, negros e gays sendo os alvos mais importantes. Seu apoio declarado à tortura ou execução sumária de traficantes de drogas e outros "elementos criminosos extremos" ecoa o presidente Rodrigo Duterte, das Filipinas.

O caráter extremo das posições de Bolsonaro levanta a questão da relação entre sua ascensão e os interesses do capital. Sua ascensão contradiz a presunção do poderoso papel do capital na definição de resultados políticos? Pode-se argumentar que, incapaz de reunir até um mínimo de apoio a seus veículos partidários preferidos e não dispostos a aceitar outro governo do PT sob nenhuma circunstância, as elites econômicas ficaram desamparadas diante dessa persona "populista" descomunal. A interpretação das "elites de olhos vendados" negligencia, no entanto, um elementochave na ascensão de Bolsonaro.

Na sequência da emergência de Bolsonaro, a figura de Paulo Guedes rivaliza com a do juiz Sergio Moro. Se Moro e seus aliados judiciais fizeram o trabalho negativo de remover Lula, Guedes fez o trabalho positivo de construir a confiança do capital de que a agenda econômica de Bolsonaro serviria a seus interesses.

Guedes é um genuíno "garoto de Chicago". O doutorado em economia na Escola de Chicago é apenas o começo. Mais importante, as políticas que ele defende são diretamente do manual "neoliberal" tradicional. Guedes olhou para as políticas econômicas chilenas como modelo durante os anos 80 e ocupou um cargo universitário no Chile durante a ditadura de Pinochet. Sua agenda projetada de 
políticas econômicas inclui concluir os esforços para minar a rede de seguridade social, atacando o sistema de proteção social. Guedes pode ser um defensor ingenuamente ambicioso das políticas de livre mercado que atendem à elite financeira, mas ele forneceu a Bolsonaro o "selo de aprovação" econômico necessário e removeu, no setor financeiro, a mancha de uma possível afinidade com o "estatismo" criada pela carreira política de Bolsonaro. Após o anúncio de novembro de 2017 de que Guedes seria ministro da Economia de Bolsonaro, ficou claro que a agenda econômica do novo governo seria uma continuação mais ambiciosa da agenda de Temer. ${ }^{7}$

Em sua versão pós-Guedes, a agenda de Bolsonaro ecoa a fórmula clássica de políticos fascistas de sucesso na era anterior à Segunda Guerra Mundial, que combina autoritarismo político, repressão e reação social com forte apoio ao capitalismo e às prerrogativas dos capitalistas, evitando o típico nacionalismo centrado no estado que caracterizou os principais membros do governo militar da década de 1970.

Mesmo diante da porta aberta por Moro e da legitimidade aos olhos do capital financeiro proporcionada por Guedes, ainda é um desafio explicar o sucesso eleitoral de Bolsonaro. Se a aceitabilidade para financiar capital fosse suficiente, Henrique Meirelles teria recebido mais de $1 \%$ dos votos na primeira rodada do concurso presidencial. Meirelles passou 28 anos formativos trabalhando no Banco de Boston, foi escolhido por Lula para legitimar o capital global como presidente do Banco Central e foi ministro da Fazenda de Temer (2016-2018). Os especialistas em finanças como especialistas em finanças são muito superiores aos de Guedes (não diga nada a Bolsonaro). Obviamente, o apoio ao capital, mesmo que necessário, está longe de ser suficiente.

Se a tragédia política trará lições úteis para o futuro, não apenas para o Brasil, mas para a lista global de países que enfrentam ameaças análogas, o nível assustador de apoio popular aos valores políticos completamente retrógrados de Bolsonaro deve ser analisado com cuidado e desapego. Aqui, apenas a resposta mais hesitante e insatisfatória é possível.

A dimensão mais desanimadora do apoio de Bolsonaro é a facilidade com que a raiva legítima dos brasileiros comuns foi desviada daqueles que controlam o poder econômico. Explorada e maltratada pelo capitalismo brasileiro, a classe média brasileira optou por culpar os ainda mais despossuídos e oprimidos que se beneficiaram das políticas redistributivas do PT. Uma compreensão satisfatória de como isso foi possível ainda permanece além do nosso alcance, mas elementos do enigma podem ser estabelecidos.

Para começar, permanecem linhas históricas profundamente hierárquicas da cultura brasileira. Como a Presidente Dilma Rousseff disse em seu discurso de abril: “Nosso povo sofreu muito. Eles sofreram sob a herança de 300 anos de escravidão. E a elite sempre pensou que essas pessoas não apenas não têm direitos, como também não têm o direito de estar lá". Essa afeição pela hierarquia se estende além da elite. 
O ressentimento contra as reformas redistributivas do PT permeava os segmentos mais brancos e mais ricos da classe média, alguns dos quais, como observou Dilma, reclamaram que o PT estava "transformando os aeroportos em rodoviárias porque as pessoas comuns começaram a voar". Um número surpreendente de membros instruídos da classe média considerou o fato de que "35\% de todos os graduados da universidade foram os primeiros de suas famílias a obter um diploma universitário", como uma afronta aos valores meritocráticos. E, é claro, os fios retrógrados na consciência política popular foram ampliados e exacerbados por uma ladainha na mídia de que os problemas do Brasil poderiam ser resolvidos pela simples combinação de punir a corrupção (daí a necessidade de rejeitar todo o espectro da política existente) e punir a violência (daí a necessidade de sujeitar os pobres à repressão irrestrita).

Ao mesmo tempo, ironicamente, o descontentamento com os políticos estabelecidos (mesmo aqueles com agendas progressistas) refletia a frustração acima dos limites do que foi alcançado em termos de melhorias reais na vida das pessoas comuns durante os "anos dourados" do PT. A aparente ineficácia das instituições democráticas normais legitimou "medidas extraordinárias" como as propostas por Bolsonaro.

Existe algum contraponto convincente ao que parece ser um horizonte político incessantemente sombrio no Brasil? Talvez não, mas seria irresponsável fechar deixando a impressão de que o Brasil deve ser abandonado como causa perdida. Mesmo no meio da desolação, threads positivos devem ser recuperados.

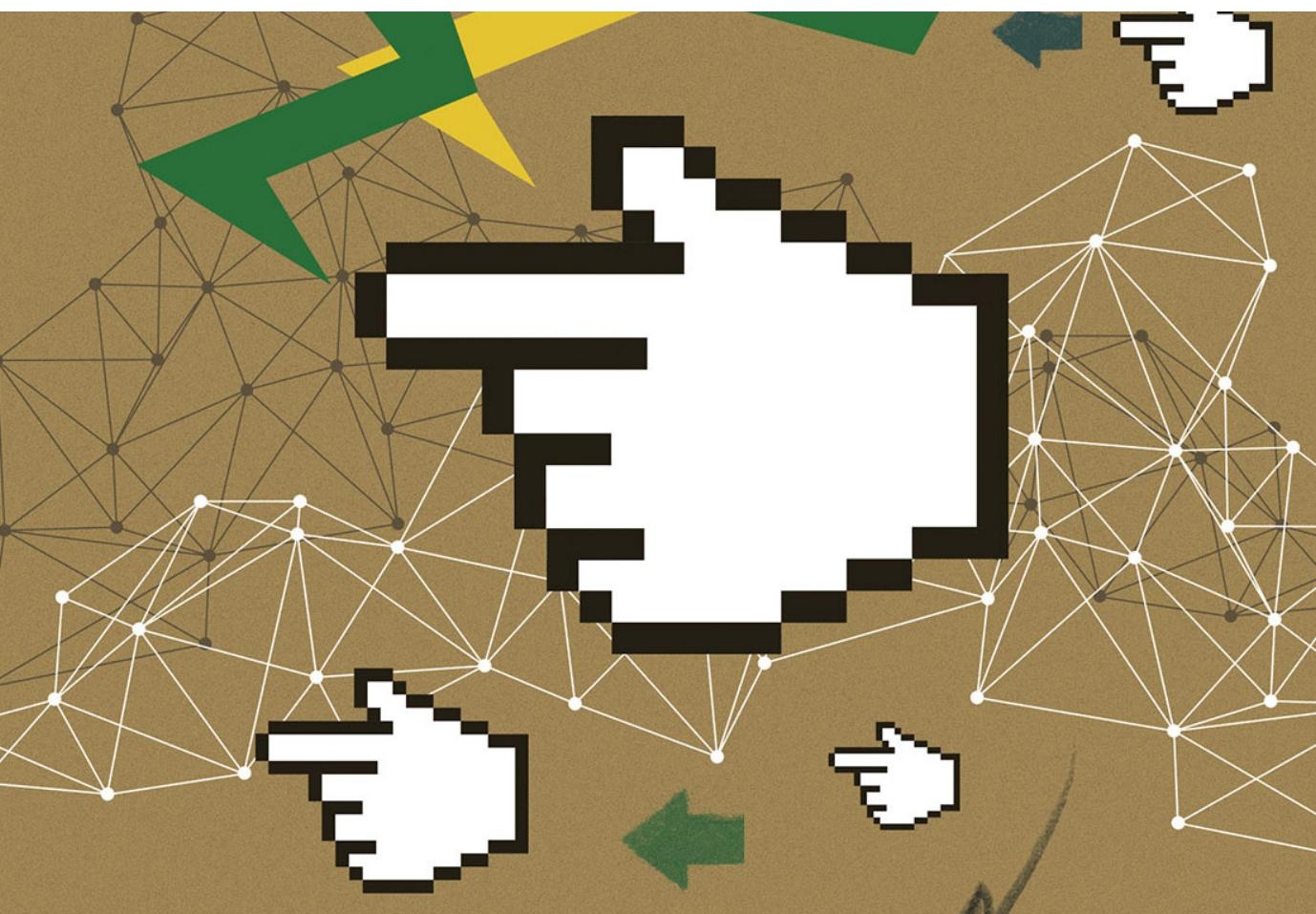


Primeiro, no contexto atual, o candidato substituto do PT apressadamente, Fernando Haddad, teve um desempenho melhor do que o PT tinha motivos para esperar. Enquanto os candidatos presidenciais do PMDB e PSDB foram imolados por Bolsonaro na primeira rodada de votação, Haddad garantiu votos nos estados da região mais pobre do país, o Nordeste, sugerindo que ainda existe um segmento substancial da população que aprecia seus ganhos durante as administrações do PT e apoiaria um esforço renovado para retomar uma agenda progressista.

Em segundo lugar, as instituições progressistas construídas durante a luta pela redemocratização nas três décadas subsequentes, embora definitivamente sitiadas, podem não ser tão facilmente destruídas quanto Bolsonaro e a elite brasileira podem esperar. Desde a Constituição Federal de 1988 até a pletora de iniciativas democráticas que borbulharam e se tornaram parte do cenário institucional do Brasil (AVRITZER, 2002; BAIOCCHI, HELLER E SILVA, 2011), existem inúmeros pontos de apoio de resistência à maré reacionária.

O Brasil ainda é o lar de movimentos sociais admirados em todo o mundo, por exemplo, o MST (Movimento dos Trabalhadores Rurais Sem Terra; ver Tarlau, no prelo), GuilhermeBoulos, líder do análogo urbano do MST, (MTST, o Movimento dos Trabalhadores Sem-Teto) ${ }^{8}$, exibiu um carisma durante a campanha presidencial que ultrapassou em muito seus totais eleitorais. E, apesar de ser ridicularizado por seus críticos da esquerda como insuficientemente militante, o movimento trabalhista brasileiro ainda está entre os melhores organizados. Por fim, os quadros repressivos de Bolsonaro farão o possível para reduzir o aumento progressivo das bases, bem como o legado de Marielle Franco, a vereadora negra e abertamente gay que foi assassinada no Rio de Janeiro alguns meses antes da eleição. Contudo, mais Marielles do que eles esperam passarão por suas redes - assim como os militantes conseguiram sobreviver durante o regime militar que travou a última rodada de repressão meio século atrás. A própria Dilma Rousseff é um exemplo de resiliência política. Em seu discurso em Berkeley, quando perguntada se ela continuava encontrando motivos para otimismo, ela respondeu que está envolvida na política desde os 15 anos de idade e que foi presa e torturada por três anos; seu otimismo ainda está fundamentado em sua convicção de que "não somos apenas seressociais, somos cooperadores. Não é a competição que define as relações sociais. É a cooperação. Essa convicção me faz uma'otimista da vontade ${ }^{\prime \prime \prime}$. Emergindo da derrota na disputa do Senado em 2018, Dilma Rousseff permaneceu determinada como sempre, dizendo: "Agora devemos lutar para formar uma ampla aliança em apoio à democracia e contra a desigualdade. Vamos marchar juntos contra o ódio, o atraso e a violência."10 


\begin{abstract}
Notas
'Esse artigo é uma versão traduzida com autorização do autor do artigo "Brazil. An ongoing trajedy", publicado originalmente na Berkeley Review of Latin American Studies, Fall 2018, p. 8-13. Traduzido por Flavio Gaitán (UNILA) e Carlos Eduardo Santos Pinho (UNISINOS).

2 Estudo de Saboia (2007) citado por Berg (2010, p.14). Para uma discussão mais recente do impacto do aumento do salário mínimo, ver: Kerstenetzky, 2017.

${ }^{3}$ Ver: http://www.worldbank.org/en/country/brazil/overview\#1. Acesso em: 10 Out. 2019.

${ }^{4}$ Ver, por exemplo: Eduardo Porter https://nyti.ms/2VwxdHQ. Ver: https://nyti.ms/2OXYqPE. Acceso em: 10 Out. 2019

${ }^{5}$ Ver, por exemplo: Bastos 2017, 2018; Braga, 2016a, 2016b; Braga and Purdy, 2018; and Singer, 2012, 2016.

${ }^{6}$ Há uma ampla literatura sobre o caso Lula. Um dos volumes mais interessantes é de Proner et al., 2018, o qual inclui o comentário e analise de acadêmicos do direito e das Ciencias Sociais.

${ }^{7}$ Para um breve perfil de Guedes, ver: https://bit.ly/2wIRTHO. Acesso em: 15 Out. 2019.

${ }^{8}$ Ver: http://www.mtst.org. Acesso em: 15 Out. 2019.

${ }^{9}$ Ver: https://glo.bo/32KtsQv. Acesso em: 15 Out. 2019.

${ }^{10}$ Ver: https://glo.bo/39dHtc5. Acesso em: 15 Out. 2019.
\end{abstract}

\title{
Referências
}

AVRITZER, L. Democracy and the Public Space in Latin America. Princeton: Princeton University Press, 2002.

BAIOCCHI, G, P. HELLER \& KUNRATH SILVA, M. Bootstrapping Democracy: Transforming Local Governance and Civil Society in Brazil. Stanford University Press, 2001.

BASTOS, P. P. Z. Ascenção e crise do governo Dilma Rousseff e o golpe de 2016: Poder estrutural, contradição e ideologia. Revista de EconomiaContemporânea, v. 21, n. 2, p. 1-63, 2017.

BASTOS, P. P. Z. Brazil at crossroads: The Rousseff impeachment and the neoliberal takeover in historical perspective. Unpublished Ms, 2018.

BERG, J. "Laws or Luck? Understanding Rising Formality in Brazil in the 2000s." WorkingPaper No. 5, Decent Work in Brazil Series, International Labour Organization, Brasilia, 2010. Disponível em: https://bit.ly/38v3F0K. Acceso em: 15 Out. 2019.

BRAGA, R. A política do precariado: Do populismo à hegemonial ulista. São Paulo: Boitempo, 2012.

BRAGA, R. The End of Lulism and the Palace Coup in Brazil. Global Dialogue, v. 6, n. 3, September, 2016a. Available at: https://bit.ly/2UQO1sz. Acseso em: 15 Out 2019.

BRAGA, R. Terra em transe: $O$ fim do lulismo e o retorno da luta de classes. In A. Singer \& A. Loureiro (Eds.), As contradições do lulismo: A que pontochegamos? (pp. 55-92). São Paulo: Boitempo, 2016b..

BRAGA, R. \& PURDY, S. A precarious hegemony: neoliberalism, social struggles, and the end of Lulismo in Brazil, Globalizations, 2018.

BRAZILIAN MINISTRY OF PLANNING (Economic Advisory Office). Brazilian Development Indicators. Brasília, DF, Brazil, 2014.

EVANS, P. National Labor Movements and Transnational Connections: Global Labor's Evolving Architecture Under Neoliberalism. Global Labour Journal, v. 5, n. 3, p. 258-282. September, 2014.

FLEURY, S. \& PINHO, S. Authoritarian Governments and the Corrosion of the Social Protection Network in Brazil. R. Katál., Florianópolis, v. 21, n. 1, p. 29-42, jan./abr, 2018. 
KERSTENETZKY, C. L. Foi Um Pássaro, Foi Um Avião? Redistribuição no Brasil no século XXI1. Novos Estudos CEBRAP, v. 36, n. 2, p. 15-34, julho, 2017.

MCKENNA, E. Brazil. The life and death of the new republic. Berkeley Review of Latin American Studies, p. 14-20, fall 2018.

OLIVEIRA, R.V. Brazilian Labour Reform in Historical Perspective. Global Labour Journal, v. 9, n. 3, p. 319-338, 2018.

PRONER, C., G. CITTADINO, G. RICOBOM \& J. R. DORNELLES (organizers). Comments on a notorious verdict: The trial of Lula. Project supported by Instituto Joaquim Herrera Flores, Instituto Declatra, Instituto Defesa da Classe Trabalhadora, Instituto Novos Paradigmas \& CLASCSO, 2018. Based on Comentarios a uma sentença anunciada. O Processo Lula. 2017. Coordenação, Giovanni Alves. Editora Canal 6, Projeto Editorial Praxis.

SABOIA, J. Salário minimo e distribução da renda no Brasil no periodo 1995-2005: fatos e simulações. In: SEMINÁRIO DE ANÁLISIS DA PNAD, CGEE/IPEA/MEC/MTE, 2., 2007, Brasília, 2007.

SINGER, A. Os sentidos do lulismo: Reforma gradual e pactoconservador. São Paulo: Companhia das Letras, 2012.

SINGER, A. A (falta de) base política para o ensaio desenvolvimentista. In A. Singer \& I. Loureiro (Eds.) As contradições do lulismo: A que pontochegamos? (pp. 21-54). São Paulo: Boitempo, 2016.

SLUYTER-BELTRÃO, J. Rise and Decline of Brazil's New Unionism: The Politics of the Central Única dos Trabalhadores. Oxford: Peter Lang, 2010.

TARLAU, R. Occupying Schools, Occupying Land:How the Landless Workers Movement Transformed Brazilian Education. Oxford University Press, 2019.

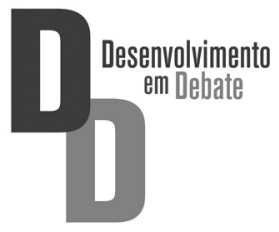

